\title{
Geo-Chemical Techniques for Earthquake Forecasting in Nigeria
}

\section{Lungfa Collins Wuyep ${ }^{1^{*}}$, Umar Afegbua Kadiri ${ }^{1}$, Isogun Adeyemi Monday ${ }^{1}$, Nanshin Emmanuel Nansak ${ }^{2}$, Lumi Zakka ${ }^{1}$, Habila Yusuf Thomas ${ }^{3}$ and Ezisi Pius Ogugua ${ }^{1}$}

${ }^{1}$ Earthdynamics Division, Siesmology Unit, Centre for Geodesy and Geodynamics, Toro, Bauchi State, Nigeria.

${ }^{2}$ Zonal Advance Space Technology Applications Laboratory. Kashere, Nigeria. ${ }^{3}$ Department of Nuclear energy, Proten-Federal University of Pernambuco, Recife--PE Brazil.

Authors' contributions

This work was carried out in collaboration among all authors. All authors read and approved the final manuscript.

Article Information

DOI: $10.9734 /$ AJGR/2021/v4i394

Editor(s):

(1) Dr. Xu Chong, Institute of Geology, China.

Reviewers:

(1) Zia Ur Rehman, University Of Karachi, Pakistan.

(2) Gokul Raghavendra Srinivasan, VIT university, India. Complete Peer review History: https://www.sdiarticle4.com/review-history/72897

Review Article

Received 25 June 2021

Accepted 31 August 2021

Published 03 September 2021

\section{ABSTRACT}

Regardless of the doubt caused by some rounds on the impossibility of earthquake forecast, more and more countries, even at the highest governmental levels, realize that doing nothing is the ostrich position of dread before the real difficulties associated with the creation of a real forecasting system. Nigeria in times past was believed to be aseismic. However, the seismic record of Nigeria from 1933-2021 have demonstrated in contrast to the idea, numerous quakes have been recorded in Nigeria throughout the years. With the development of observation techniques and theoretical knowledge of geochemistry, geochemical observation of faults gas has become a hotspot once more in recent years. $\mathrm{Rn}, \mathrm{Hg}, \mathrm{H}_{2}$, etc., are used for geochemical observations. ${ }^{222} \mathrm{Rn}$ has a half-life of 3.825 days, a magnitude 5.0 earthquake will be detected through precursory phenomena at a distance not greater than $142 \mathrm{~km}$. Mercury and other elements are used as important detectors for earthquake prediction and they play an important role in revealing the relationship between fluid in the fault zone and the occurrence of earthquakes, the range for a magnitude 5.0 earthquake is 
limited to $200 \mathrm{~km}$. Hydrogen concentrations have been monitored for precursory variations in many fault systems, using either discrete sampling and laboratory analysis or continuous monitoring of ground gas, using hydrogen-sensitive fuel cells. Precursory changes in groundwater chemistry are often attributed to the mixing of fluids from two or more chemically distinct aquifers, the physical mechanism responsible for the mixing of fluids is, however, not well established.

Keywords: Earthquakes forecast; seismology; seismic activity in Nigeria; geochemistry; hydrogen; mercury; radon.

\section{INTRODUCTION}

Earthquakes are the most feared of consistent dangers since they happen all of a sudden. Tropical storms can be followed, floods grow step by step, and volcanic expulsions are gone before by a mixture of preceding wonders. Earthquakes, in any case, by and large happen with no notice. There have been a wide variety of approaches applied to the anticipating of Quakes (Mogi, 1985; Turcotte, 1991; Lomnitz, 1994; Keilis-Borok, 2002; Scholz, 2002; Kanamori, 2003). The events of geochemical inconsistencies delivered by quakes were first found at Tashkent in the previous Soviet Union, although notable examinations were conducted in Japan, [1]. Broad tremor expectations examined have been done in Russia, China, and Japan just as in other dynamic seismic locales in the USA, India, Italy, and so on. In actuality, not many quakes expectation research has been carried out in mainland zones that are named stable areas for seismicity despite the likely harm of unforeseen quakes on account of helpless structure practice.

Nemesio et al., [1]. Reported, Quakes remain commonly inconsistent and their occurrences are typically connected with extreme collapse and a huge measure of loss, which is because of the nonlinear idea of its elements and this has made Research in earthquake forecast a troublesome undertaking since these initial marks are difficult to distinguish. Despite these threatening conditions, geochemical perceptions have given critical and promising outcomes to earthquake forecast research during the most recent 30 years [2-5]. Nigeria in times past was believed to be aseismic. In any case, the seismic record of Nigeria from 1933 till date has demonstrated in contrast to the idea [6]. Numerous quakes have been recorded in Nigeria throughout the years. Since 1923 when the first tremor was felt in the country, over thirty-nine (39) events have been reported. Of these 39 seismic events, less than $20 \%$ were recorded instrumentally. The tremors felt in more than one locality at a time is estimated to be over forty-eight (48) instances and experienced in various communities cutting across about twenty-two (22) states of the federation including the Federal Capital City, Abuja giving a percentage coverage of about $60 \%[1]$.

These quakes are dispersedly scattered through the geo-political zones in Nigeria. Nigeria as a nation has six geo-political zones to be specific the North-Central Zone, North-East Zone, NorthWest Zone, South-East Zone, South-South Zone and the South-West Zone. As of late on the 11th of September 2009 around 03:10:30 am in Abeokuta, a quake with a magnitude of 4.8 was recorded, [6]. Scientists from the Centre for Geodesy and Geodynamics (CGG) by confirmation on the evaluation of quakes found out that Nigeria is not a nation that is free from earthquake danger, spotlight have been on this unworried condition in the country. The southwest district of Nigeria has been encountering more quakes among other geopolitical zones in Nigeria [7-12]. This is a pointer to the way that this zone is inclined to earthquakes among different zones in Nigeria. The quake was forecast by certain scientists and headed by Dr. Adepelumi Adekunle Abraham, of the Department of Geology, Obafemi Awolowo University, lle Ife. Their report was named, Preliminary Assessment of Earth Tremor Occurrence in Shaki Area, Shaki West Local Government, Oyo State, showing an approaching risk. The head of The Nigerian Association of Water-Well Drilling Rig Owners and Practitioners (AWDROP) likewise expressed to the legislature that the absence of guideline towards underground water extraction can be a wellspring of startup earthquake, in this manner there ought to be an exacting consistence in the code of training usage [6]. No piece of the world is resistant to quakes, as can be found in the Figure below, most earthquakes are focused on the mainland plate limits, the "ring of fire" around the Pacific Rim or the African Rift zone running from the core of Africa through the Red Sea, Dead Sea, the Jordan River Valley and the 
Himalayan lower regions, for instance. In any occurrences a million earthquakes, huge and little, happen worldwide consistently [13,14]. The bunches of dark dabs (focal points of quakes) in the Fig. below help the basic idea that tremors will consistently come back to a similar spot or close to enough after some time. This turned into the conventional way to deal with earthquake forecast created by Reid [15].

A few geochemical peculiarities were seen before the Haichen (1975) earthquake, This earthquake had a Magnitude of 7.5 and a depth of 15, $600 \mathrm{~km}$, Longling (1976) earthquake, in Yuang Province, People's Republic of China, a doublet earthquake with Magnitudes of 7.4 and 7.3, and depths of $12.2 \mathrm{~km}$ and $16.7 \mathrm{~km}$ respectively according to Chinese sources, Tangshan (1976) The earthquake had a Magnitude of 7.6, and a depth of $\mathrm{km}$ and Songpan (1976) This is consist of three mainshocks with Magnitudes of 7.0, 6.6 and 6.7, depths of $8 \mathrm{~km}, 15 \mathrm{~km}$ and $19 \mathrm{~km}$, respectively, quakes and their solid delayed repercussions (Wikipedia 2020. China has built a systematic monitoring network of groundwater for earthquake forecast in the past 50 years. It contains hydrogen chemical observation stations ( $\mathrm{Rn}, \mathrm{H}_{2}, \mathrm{Hg}$, ion composition, etc.), groundwater observation stations (water level, flux) and geothermal observation stations (water temperature, ground temperature). Up to now, more than 684 observation stations have been set up in almost all provinces of China, with a total of 1522 observation items, including 486 water level observations, 465 water temperature observations, 219 radon observations, 15 hydrogen observations of faults, 73 mercury observations and 264 other observations [16].

\subsection{Review of Earthquakes in Nigeria}

[17] Despite the fact that Nigeria is not situated within the primary seismic zones of the world; over the years, multiple minor quakes have been experienced in some parts of the country. The first widely reported incident of an Earth tremor in Nigeria was in 1933. Other events were reported in 1939, 1964, 1984, 1990, 1994, 1997, 2000 and 2006. The intensities of these events spread from III to VI based on the Modified Mercalli Intensity Scale. Of these events, only the 1984 , 1990, 1994 and 2000 events were instrumentally recorded. They had body wave magnitudes ranging from 4.3 to 4.5 , local magnitudes between 3.7 and 4.2 , and surface wave magnitudes of 3.7 to 3.9 . When these events occurred, there were no functional seismological observatories in Nigeria. However, that has now changed with the establishment of a seismographic network managed by the Centre for Geodesy and Geodynamics (CGG), Toro, Nigeria. Currently, the network has four operational stations equipped with 24-bit 4channel recorders and broadband 30-second seismometers. Attempts are being made to establish more stations and migrate to real-time collection of seismic data using the general packet radio service (GPRS) technology as well as automatic location of events. Remote sensing, geological and geophysical studies have revealed the presence of a NNE-SSW trending Ifewara-Zungeru fault zone which is linked with the Atlantic fracture system. The dynamics of the Atlantic fracture zones have been suggested to be responsible for the seismic activities experienced in the areas [17].

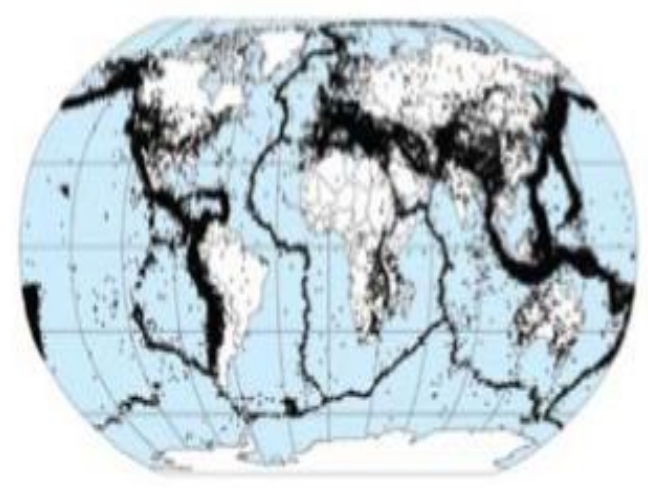

Fig. 1. Preliminary determination of epicenters 358, 214 events 1963-1998 
[6]. Adekunle Adepelumi, a professor of geophysics at Obafemi Awolowo University, IleIfe, Osun, said an earth tremor - a moderate earthquake - was recorded in the state. In a preliminary report, Adepelumi said the earth tremor, which was recorded around 11am on June 5, 2021 measured 2.6 in moment magnitude and 2.4 in local magnitude on the Richter scale, while it had a focal depth of $15 \mathrm{~km}$. Chukwudi Njoku, a geographer and researcher at the University of Calabar, told The Cable that Nigeria needs to be more vigilant in case of severe incidents, because going by the report, the fault system that led to the tremor is still active. Another earthquake had occurred in Abuja in 2018. According to investigations carried out by scientist from the Centre for Geodesy and Geodynamics, the main earthquake which occurred on Friday $7^{\text {th }}$ September 2018 at 5:11:32 am with a moment magnitude of 2.6 and a local magnitude of 3.0. while the foreshocks and aftershocks were experienced on Wednesday and Thursday, as well as Friday and Saturday respectively. The foreshock and aftershocks all had a magnitude of less than 3.0. Professor Mohammed explained that the stress drop from the main earthquake was $2.1 \mathrm{bar}$, and the length of fault displacement was computed as 0.56 kilometers, while the rupture or focal depth of the earthquake was estimated between 10 kilometers and 15 kilometers. "When personnel of the agency interacted with residents of Mpape and its environs, they gathered that this was not the first time the shaking has occurred but has happened five years ago". The exploration set up Nigeria as a nation with low seismicity with the degree of future quake that is as high as 7.2 in her southwest area. Fig. 3 shows the possible fault lines in Nigeria according.

It is surely imaginable to contend out the way that Nigeria, a locale with low seismicity can never encounter a quake of such greatness. All things considered, Antarctica as locale confirmed to be with least seismicity on the planet encountered a quake of 8.1 extent in 1998. Thus, Nigeria in spite of being a low seismic nation can encounter quakes as assayed by scientists [6]. Hydrological and geochemical changes have been studied extensively in China for the purpose of earthquake forecast since 1966. Parameters studied include water level; water temperature; and radon, hydrogen and mercury concentrations. Significant changes have been observed before some large or even intermediate-sized earthquakes, among many cases that did not show any such changes. Background noise caused by other environmental irregularities and possible mechanisms for the pre-earthquake anomalies are discussed. Due to the complexity of earthquake prediction, much more monitoring efforts as well as sophisticated analytic and synthetic efforts are needed in the future [6].

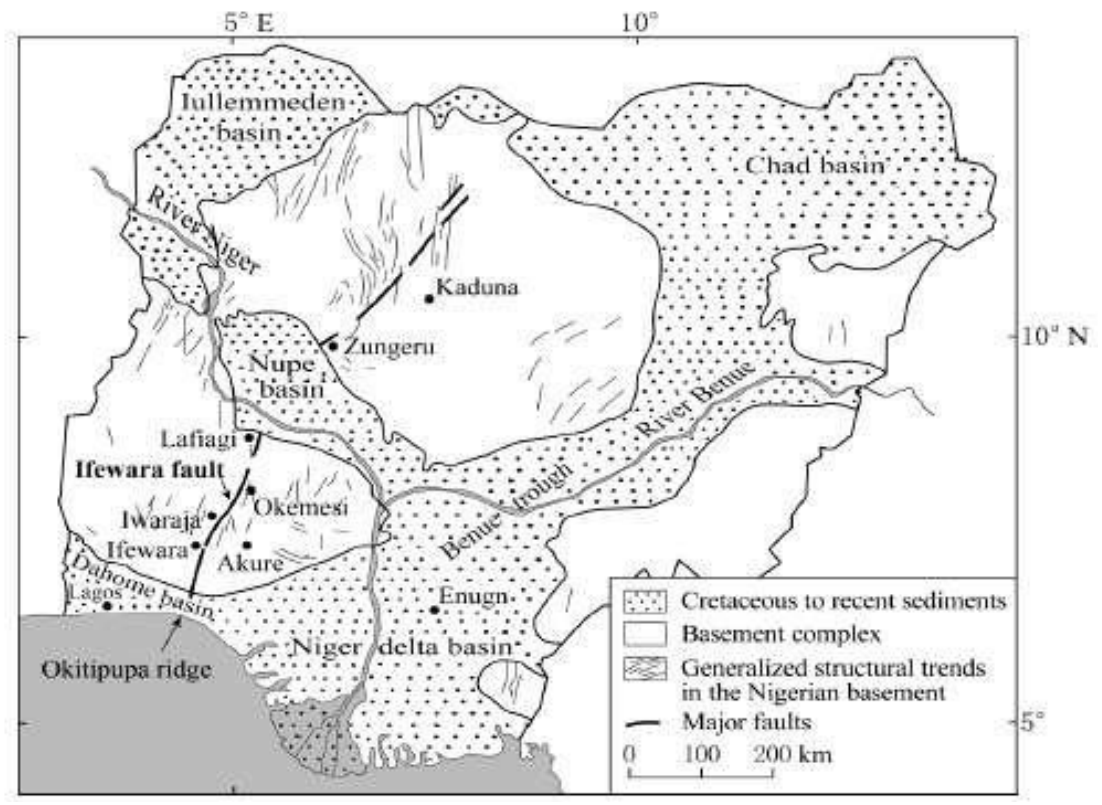

Fig. 2. Possible fault lines in Nigeria (Centre for Geodesy, and Geodynamics 2015) 
Table1. Statistical analysis of the spread of seismic events in Nigeria

\begin{tabular}{|c|c|c|c|c|c|c|c|c|c|c|c|c|}
\hline \multicolumn{13}{|c|}{ Simple Statistical Analysis of the Spread of Seismic Events in the Country } \\
\hline \multirow[t]{2}{*}{$\begin{array}{l}\mathbf{S} \\
1 \\
\mathbf{N}\end{array}$} & \multicolumn{2}{|c|}{$\begin{array}{l}\text { North- East } \\
\text { (NE) }\end{array}$} & \multicolumn{2}{|c|}{$\begin{array}{l}\text { North West } \\
\text { (NW) }\end{array}$} & \multicolumn{2}{|l|}{$\begin{array}{l}\text { North- } \\
\text { Central } \\
\text { (NC) }\end{array}$} & \multicolumn{2}{|c|}{$\begin{array}{l}\text { South-East } \\
\text { (SE) }\end{array}$} & \multicolumn{2}{|c|}{$\begin{array}{l}\text { South-South } \\
\text { (SS) }\end{array}$} & \multicolumn{2}{|c|}{$\begin{array}{l}\text { South-West } \\
\text { (SW) }\end{array}$} \\
\hline & State & Freq & State & Freq. & state & Fre & State & Freq. & State & Freq & state & Freq \\
\hline 1 & $\begin{array}{l}\text { Adama } \\
\text { wa }\end{array}$ & 2 & $\begin{array}{l}\text { Kadu } \\
\text { na }\end{array}$ & 3 & Abuja & 2 & Abia & 2 & Delta & 1 & Ogun & 9 \\
\hline 2 & Bauchi & 2 & $\begin{array}{l}\text { Zamf } \\
\text { ara }\end{array}$ & 1 & Niger & 1 & $\begin{array}{l}\text { Ana } \\
\text { mbra }\end{array}$ & 1 & $\begin{array}{l}\text { Bayel } \\
\text { sa }\end{array}$ & 1 & Oyo & 8 \\
\hline 3 & Gombe & 2 & Kano & 1 & Benue & 1 & & & Edo & 1 & $\begin{array}{l}\text { Lago } \\
\mathrm{s}\end{array}$ & 4 \\
\hline $\begin{array}{l}4 \\
5\end{array}$ & Taraba & 2 & & & & & & & Rivers & & $\begin{array}{l}\text { Ekiti } \\
\text { Osun }\end{array}$ & $\begin{array}{l}2 \\
1\end{array}$ \\
\hline 6 & & & & & & & & & & & Ondo & 1 \\
\hline & 4 & 8 & 3 & 5 & 3 & 4 & 2 & 3 & 4 & 4 & 6 & 25 \\
\hline
\end{tabular}

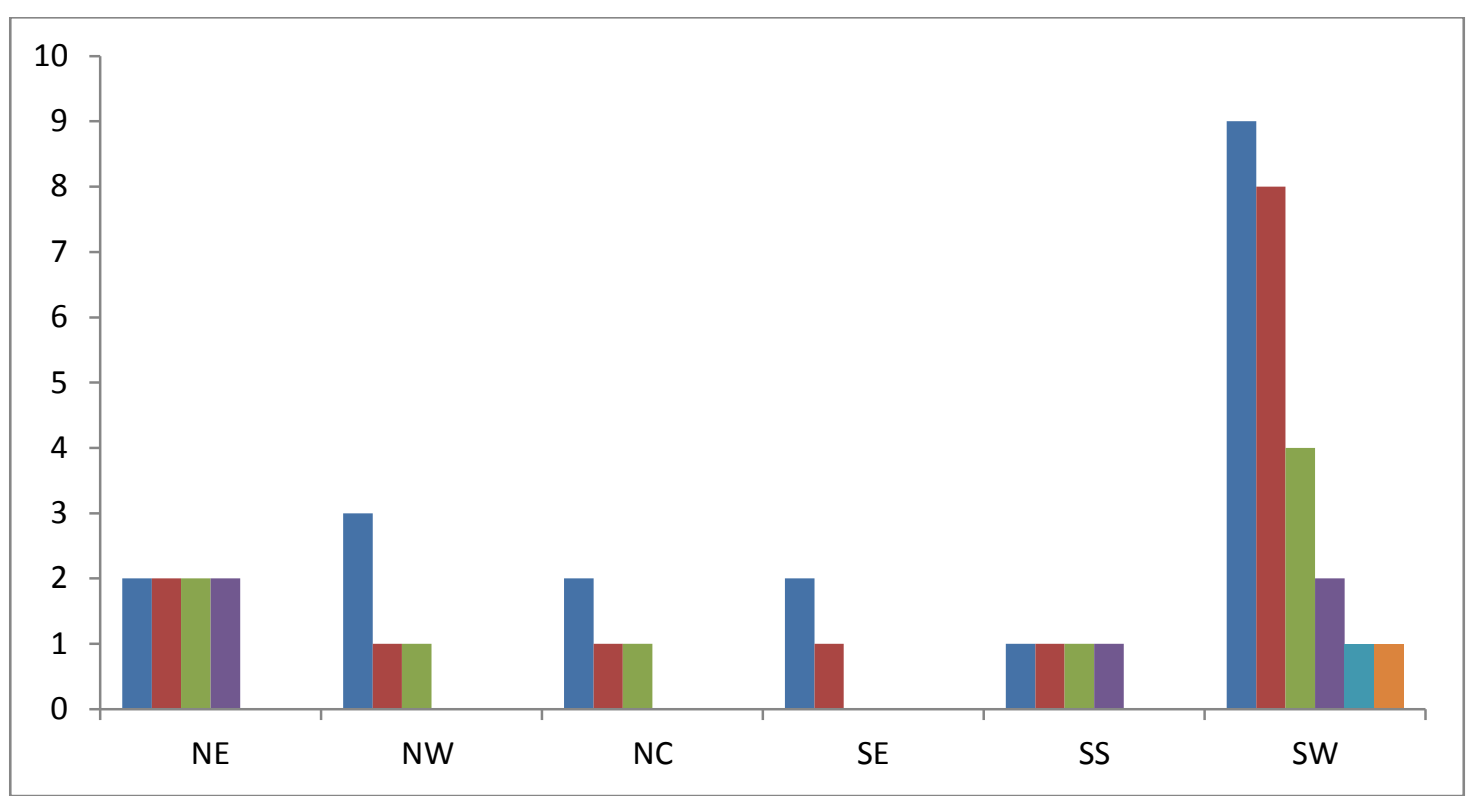

Fig. 3. Bar charts of the spread of seismic events in Nigeria

The Centre of Geodesy and Geodynamics, Toro in Bauchi State, reports that the average value of intensities for Nigerian Earthquakes ranges from III $-\mathrm{VI}$ on the Modified Mercalli Scale. The ML is averaged at $3.7-4.2 \mathrm{Mp}$ is averaged at $4.3-4.5$ and MS is averaged at $3.7-3.9$. The causes of tremors in Nigeria are attributed to several factors. Tsalha [18] and Eze et al., [19] argues that stresses that builds up around plate boundaries could travel towards the centre of the plates triggering intraplate tremors especially in pre-existing faults. attribute the seismicity majorly to regional stress and zone of weakness in the crust or transfer of stress from plate boundaries, considering the fact that the coastal area of
Nigeria lies in close proximity to the boundary between the African plate and South American plate implied that some of the tremors that occurred in the coastal areas of Nigeria could have been possibly initiated by this process. The stresses built up around plate boundaries could travel towards the center of the plate, triggering intraplate tremors especially in pre-existing faults $[20,21]$.

\section{METHODOLOGY}

Research on fault gas was initiated in the 1980s and attracted widespread scientific interests. With the development of observation techniques 
and theoretical knowledge of geochemistry, geochemical observation of faults gas has become a hotspot once more in recent years. $\mathrm{Rn}, \mathrm{Hg}, \mathrm{H}_{2}$, etc., are used for geochemical observations [21].

\subsection{Radon}

Radon is the decay daughter nuclide of radioactive uranium, radium and thorium in the crust. There exist three radioactive isotopes of radon in nature: ${ }^{219} \mathrm{Rn},{ }^{220} \mathrm{Rn},{ }^{222} \mathrm{Rn} .{ }^{222} \mathrm{Rn}$ has a half-life of 3.825 days, while the other two have a half-life of 3.96 and $55.65 \mathrm{~s}$, respectively. The two isotopes with half-life 3.96 and $55.65 \mathrm{~s}$ are not suitable for earthquake research, because they have a relatively short half-life, the one, the authors studied was ${ }^{222} \mathrm{Rn}$. Radon migration is closely related to the external environment. The active fault zone, because of the large porosity and high permeability, becomes a good relocation and concentration channel of fault gas. Since the discovery of radon concentration that escaped from the upper part of the fault has been linked to seismic activity in the 1970s, many scientists have begun to observe changes in radon concentrations to forecast earthquake [22]. In 1968, the first geochemical observation station in China was established in Xinji, Hebei province [23]. Later, a comprehensive observation station was established in Xiaotangshan, Beijing, especially for the observation of dissolved radon in hot water [24]. In the middle 1990s, the successful development of the digital SD-3A automatic radon measurement instrument accelerated the study of radon and until now the SD-3A is still most popular for continuous observation of radon by scientists in the earthquake field in China. The production of ${ }^{222} \mathrm{Rn}$ depends on the activity concentrations of ${ }^{226} \mathrm{Ra}$ in the earth's crust, in soil, rock and water. When radium decays in a mineral substance, the resulting radon atoms must first flow from the grains into the air-filled pore space. The fraction of radon that enters the pores, commonly known as flowed fraction, consists of two components due to recoil and diffusion mechanisms. Since the diffusion coefficient of gases in solid materials is very low, it is presumed that the main portion of the flowed fraction comes from the recoil process. From the alpha decay of radium, radon atoms have sufficient kinetic energy $(86 \mathrm{keV})$ to move from the site where radon is generated. The range of ${ }^{222} \mathrm{Rn}$ is between 20 to $710 \mathrm{~nm}$ in common materials, $100 \mathrm{~nm}$ for water and $63 \mu \mathrm{m}$ for air. [25] The flowed fraction can be strongly influenced by water content in the material, increasing with soil moisture, up to saturation in the normal range of soil moisture content. A representative estimate of the fraction of radon that leaves solid grains is $25.00 \%$. The increase in the flow fraction can be explained by the lower recoil range of radon atoms in water than in air. The presence of water increases the flow fraction, but this trend may show a saturation effect or the effect may even later reverse as the water content becomes greater. A rise in temperature also causes an increase in the flow fraction, which is probably due to the reduced adsorption of radon. Different types of soil show different flow fractions for ${ }^{222} \mathrm{Rn}$, which are generally in the range $0.01-0.5$ [25].

In order to understand how radon anomalies could be matched up to geodynamic events radon transport mechanisms in soil must be considered. Different models to describe radon diffusion have been proposed.

(1) Plate sheet mode, one of the most reliable models to describe radon diffusion is the plate sheet model. The molecular diffusion is considered in only one direction and, for any stable element, can be described by Fick's second law as follows (Gauthier et al.,1999):

$\frac{\partial C}{\partial t}=D \partial^{2} C / \partial Z^{2}$

where $\mathrm{C}$ is the concentration of the element and $D$ the diffusion coefficient along $z$. This equation admits a solution $\mathrm{C}(\mathrm{z}, \mathrm{t})$ which is constrained by the initial and boundary conditions $(C=$ $\mathrm{C}_{0}$ at $\mathrm{t}=0$ and $-\mathrm{a}<\mathrm{z}<\mathrm{a} ; \mathrm{C}=0$ at $\mathrm{t}>0$ and $\mathrm{z}=$ $+a)$ :

$\mathrm{C}(z, t) \frac{4 \mathrm{Co}}{\pi}=$
$\sum_{\pi=0}^{n}\left\{\left(\frac{(-1) \mathrm{n}}{\mathrm{dx}}\right)\right\} \times \cos \left(\frac{(2 \pi+1) \pi \mathrm{z}}{2 \mathrm{a}}\right) \times \exp \left\{\left(\frac{-\mathrm{D}(2 \pi+1) 2 \pi 2 \mathrm{t}}{4 \mathrm{am} 2}\right)\right\}$

where $a$ is the half-width of the slab. In order to take into account radioactivity, equation (3) has to be modified for radon by adding a production term from its parent ${ }^{226} \mathrm{Ra}$ and a decay term, which leads to:

$\frac{\partial C R n}{\partial t}=\lambda R a C R a-\lambda R n C R n+D \frac{\partial 2 C R n}{\partial z 2}$

where $\mathrm{C}_{\mathrm{Ra}}$ and $\mathrm{C}_{\mathrm{Rn}}$ represent the concentrations (in atoms. $\mathrm{g}^{-1}$ ) and $\lambda \mathrm{Ra}$ and $\lambda \mathrm{Rn}$ the decay constants of ${ }^{226} \mathrm{Ra}$ and ${ }^{222} \mathrm{Rn}$, respectively. Defining the function $\mathrm{K}(\mathrm{z}, \mathrm{t})$ as:

$\mathrm{K}(z, t)=\left(\left(C R n(z, t)-\left(\frac{\lambda \mathrm{Ra}}{\lambda \mathrm{Rn}} \mathrm{CRa}\right)\right) \exp (\lambda \mathrm{Rnt})\right.$ 
and introducing $K(z, t)$ in equation (4) gives:

$\frac{\partial k}{\partial t}=D \frac{\partial 2 \mathrm{k}}{\partial z 2}$

which is the Fick's second law expressed for the function $K(z, t)$. Nevertheless, the solution of equation (6) cannot be merely obtained by combining the solution of the general Fick's second law (2) with the substitution (5) because the two functions $K(z, t)$ and $C_{R n}(z, t)$ do not admit the same initial and boundary conditions. These conditions are for $C_{R n}$ $(\mathrm{z}, \mathrm{t})$ :

$\operatorname{CRn}(Z, O)=C R n E q=\frac{\lambda R a}{\lambda R b} C R a \quad$ for $-a<z<a, t=O$

$C R n(z, t)=O$ for $z=-a, z=a$

(the atmosphere is considered as a reservoir of concentration $\mathrm{C}=0$ ) which means for

$\mathrm{K}(\mathrm{z}, \mathrm{t}): \mathrm{K}(Z, O)=0 \quad$ for $-a<z<a, t=0$

$\mathrm{K}(Z, t)=-C R n E q \exp R n t \quad$ for $z=-a, z=a(7)$

Fick's law is usually solved for plane sheet geometry by separation of variables but this method is unsuccessful for such initial and boundary conditions. Several studies have been done for heat conduction in a slab having an initial zero temperature and surfaces maintained at the temperature $f(t)=V \exp (v t)$ [26], obtaining:

$\mathrm{K}(\mathrm{z}, \mathrm{t})=-\mathrm{C}_{\mathrm{RnEq}} \exp \left(\lambda_{\mathrm{Rn}} t\right) \frac{\cosh \left(z \sqrt{\frac{\lambda R n}{D}}\right)}{\cosh \left(a \sqrt{\frac{\lambda R n}{D}}\right)}$

$+\frac{4 C \quad R n E q}{\pi} \quad \sum_{n=0}^{\infty} \quad \frac{\sum(-1) n \exp \left[-(2 n+1) 2 \frac{\pi 2 D t}{4 a 2}\right]}{2 n+1\left\{1+\left[\frac{4 \lambda R n a 2}{(2 n+1) 2 \pi 2 D}\right]\right\}}$
$\frac{(2 n+1) \pi z}{2 a}$

and therefore, combining with (6):

$$
\begin{aligned}
& \mathrm{C}_{\mathrm{Rn}}(\mathrm{z}, \mathrm{t})=\mathrm{C}_{\mathrm{RnEa}}=-\mathrm{C}_{\mathrm{RnEa}} \\
& \cosh \left(z \sqrt{\frac{\lambda R n}{D}}\right) / \cosh \left(a \sqrt{\frac{\lambda R n}{D}}\right)+\frac{4 C_{R n E q}}{\pi} \\
& \sum_{n=0}^{\infty}(-1)^{n} \exp \left(\left(\frac{-(2 n+1)^{2} \pi 2 \mathrm{Dt}}{4 \mathrm{a} 2}+\lambda \mathrm{Rn}\right) \mathrm{t}\right) / \\
& 2 n+1\left[1+\left(\frac{4 \lambda r n a 2}{(2 n+1) 2 \pi 2 D}\right)\right] \cos (2 n+1) \pi z / 2 a
\end{aligned}
$$

By multiplying by $\lambda_{\mathrm{Rn}}$ both sides of the equation (10), one obtains the activity of $C_{R n}(z, t)$ given in equation:

$\mathrm{C}_{\mathrm{Rn}}(\mathrm{z}, \mathrm{t})=\mathrm{C}_{\mathrm{Ra}}$
$\cosh \left(z \sqrt{\frac{\lambda R n}{D}}\right) / \cosh \left(a \sqrt{\frac{\lambda R n}{D}}\right)$
$\frac{4 C R a}{\pi} \frac{\sum_{n=0}^{\infty}(-1) n \exp \left[-\left(\frac{(2 n+1) 2 \Pi 2 D}{4 a 2}+\lambda R n\right) t\right]}{(2 n+1)\left[1+\left(\frac{4 \lambda R n a 2}{(2 n+1) 2 \pi 2 D}\right)\right]} \cos \frac{(2 n+1) \pi z}{2 a}(10)$ where $C_{R n}$ and $C_{R a}$ represent the activity of ${ }^{222} R n$ and ${ }^{226} \mathrm{Ra}$, respectively.

(2) Infinite source model is another earth model, an infinite source $\mathrm{C}_{0}$ is overlain by an overburden of thickness $h$, where no radon source exists. In this case the radon transportation equation in the overburden, where radon production rate is zero, can be written as (Wattanikorn et al., 1998):

$\frac{d 2 C}{d z 2}+\frac{v}{D} \frac{d c}{d z}-\frac{\lambda R n}{D} C=O$

where $C$ is the radon concentration at depth $z, v$ is the gas flow velocity; $D$ is the diffusion coefficient of radon, and $\lambda{ }_{\mathrm{Rn}}$ is the decay constant. The solution of (12) is:

$\mathrm{C}_{\mathrm{Rn}}=\mathrm{C}_{\mathrm{Rn} 0} \exp \left[\frac{v(h-z)}{2 D}\right] \sinh \left[\left(\sqrt{\left(\frac{v}{2 D}\right) 2}+\frac{\lambda R n}{D}\right) z\right] /$ $\sinh \left[\left(\sqrt{\left(\frac{v}{2 D}\right) 2}+\frac{\lambda R n}{D}\right) h\right]$

\subsection{Forecasting Relationship}

Earthquake forecasting means to forecast place, time and magnitude of an earthquake. From the analysis of a wide variety of radon data available from different countries and earthquakes with $M$ $<3$, Rikitake proposed an empirical correlation between the time interval $t$ between radon anomaly and earthquake occurrence and magnitude of an earthquake [27]:

$\log t=0.76 m-1.83$

The relationship was modified by Fleischer depending on the time interval: [27]:

$$
\begin{aligned}
& \log t=M-2.16 \text { for } 0,1<t<7 \text { days } \\
& \log t=0.62 M-1.0 \text { for } t>7 \text { day }
\end{aligned}
$$

Starting from the radon diffusion equation and analyzing radon data from many countries, Ramola et al. [28] proposed an empirical 
relationship to predict the magnitude of strong earthquakes $(M>5)$ :

$M=2 \log \left(\frac{\lambda R n \nabla C r n}{K T}\right)-15.26$

where $\Delta C R n$ is the anomalous variation of radon concentration, $T$ rise time for radon anomaly and $\mathrm{K}$ is a constant $(3.96 \times 10-17)$. Several models were suggested in the past to evaluate the size of the area subject to changes in the tensional state. The models are based on assumption of uniformity and isotropy of the ground or little uniformity around the focal zone. In particular, Dobrovolsky et al. [29] proposed some relationships, taking into account an ellipsoidal inclusion with a $30 \%$ of heterogeneity with respect to the surrounding ground. He obtained the following relations that connect the magnitude $\mathrm{M}$ and the maximum distance $\mathrm{R}$ that the deformation can reach with the amplitude of the deformation $\mathrm{E}$ :

$$
\begin{array}{lr}
\mathrm{E}=\frac{10^{1.5 m-9.18}}{R^{3}} & \mathrm{M}<5.0 \\
\frac{101.3 m-8.19}{R^{3}} & \mathrm{M} \geq 5.0
\end{array}
$$

On the basis of these relationships deformations that can generate an anomaly were assess to be of the order of 10-8 [30]. Since radon anomalies seem to have a local origin, it is important to consider a relationship between the magnitude and the distance to the epicenter. If the maximum possible distance $d$ between the epicenter of a forthcoming earthquake and the spring which can be influenced by this earthquake is proportional to the volume of the pre-stressed lithosphere or to the energy of the earthquake respectively, a relationship holds of the form [31]:

$M=a \circ \log (d)+b a, b=$ const

From known relationships between magnitude $M$ and the volume of the focal zone the a-value can be determined to be about 2. Dobrovolsky et al. [29] observed that precursory phenomena are not observed beyond the distance $d$, thus to estimate roughly the radius of the effective precursory display zone, they proposed the formula:

$\mathrm{d}=10 \exp 0.43 \mathrm{M}$ where $\mathrm{d}$ is in $\mathrm{km}$ and $\mathrm{M}$ is the magnitude of the earthquake. It means that a magnitude 5 earthquake will be detected by means of precursory phenomena at a distance not greater than $142 \mathrm{~km}$. By collecting and analyzing radon anomaly data Hauksson and Goddard [32] found a similar relation. It is important that all these relationships do not differ by more than $30.00 \%$ in $d$ for $M \geq 4$. But the most interesting result is that all perceived precursors are limited by a straight line which coincides practically with a computed deformation of 10-8. Summarizing the results in only one formula it is possible to estimate the magnitude-limit Mmin for the possibility of detecting a precursor anomaly at a distance $\mathrm{d}$ (in $\mathrm{Km}$ ) to be

$\mathrm{M} \geq \mathrm{Mmin}=(2.3 \pm 0.2) \log (\mathrm{d})-(0.4 \pm 0.3)$

The constants in (20) may differ for different areas, however it is a good over all approximation. Of course, the authors can expect that certain directions from the future epicenter are favored compared to others. The limit (20) must be seen as the limit for the favored directions. Another relation was proposed by Martinelli, 1992 for which:

$\mathrm{M}=2.4 \log \mathrm{d}-0.43-0.4$

While precursor time $t$ (in days) related to the magnitude $\mathrm{M}$ and the epicentral distance $\mathrm{d}$ (in $\mathrm{km}$ ) can be estimated as follows:

$\log d t=0.63 M+(-) 0.15$

Long term series analyses have revealed a relationship between the amplitude and duration of the gaseous anomaly and the magnitude $\mathrm{M}$ of the expected earthquake [33]:

$$
M=K \sqrt{S}
$$

where $\mathrm{K}$ is a correction factor and $\mathrm{S}$ is the area of the peak anomaly, thus the shape of the peak is a diagnostic parameter for the forthcoming seismic event.

\subsection{Mercury}

The invention of a method for forecasting earthquakes in seismically active areas based on recording the density of mercury vapors variability from the Earth to the atmosphere, which is a geochemical precursor of earthquakes. A regular recording of a precursor of an earthquake (the density of mercury 
variability in the soil gas, rising from the Earth) is carried out, and then the possibility of an earthquake can be forecast based on the irregular change in the value of the density of variability recorded over time. Empirical data collected during the monitoring at the observation point suggested that the content of mercury vapor in a closed cavity inside loose layers may change with an increased amplitude (10 - 1000 times) in a space of just a few hours, which correlates with subsequent earthquakes. [34].

The collected data shows that an earthquake is preceded by the appearance of a predecessor, evident in a short-term increase in the mercury content in the gas contained before the earthquake. [34]. Mercury has a bouncy chemical property with a strong redox, existing in three kinds of valence: $\mathrm{Hg}^{0}, \mathrm{Hg}^{+}$and $\mathrm{Hg}^{2+}$. Mercury plays an important role in revealing the relationship between fluid in the fault zone and the occurrence of earthquakes. The mercury in the lower crust and the upper mantle migrate to the surface along the fracture or rock fissure by the pore fluid driven by the hydraulic gradient and forms the abnormal anomalies in rock, soil and groundwater above the fault zone. Therefore, the observation of mercury concentration has been widely used for earthquake prediction and active fault detection $[35,36,37,38]$. The gaseous mercury is easily absorbed in the fault mud during the ascending process, so the mercury concentration in the fault zone is used to determine the main sliding surface and the rupture process of earthquake. Scientists found that there was a high concentration of mercury in the core samples of the main rupture of the Wenchuan M 8.0 earthquake. The content of mercury is mainly related to the degree of rock fracture and the clay mineral inside. The distribution of mercury concentration indicates that deep fluid may have played a role in the occurrence of the Wenchuan M 8.0 earthquake $[39,40]$. The extent of disintegration and the opening and closure of the fracture can cause uneven distribution of mercury, and there usually is a higher mercury concentration in the hanging wall of the fault [41]. The mercury concentrations in carbonaceous siliceous rocks are always higher $\left(>100 \mathrm{ng} \mathrm{g}^{-1}\right)$, which are related to the rising and adsorption of mercury along the fracture [42]. For the factors affecting gaseous mercury concentration, Li et al. [43] studied the soil gas in the Yanhuai basin of North China and found that the distribution of mercury was affected by factors such as regional tectonics, stratigraphy and gas exchange rate.
The mercury in the soil is also affected by temperature. The vaporing content of mercury in the soil is reduced as a result of the enhanced adsorption of solids in winter, and when the soil temperature rises in spring, the absorbed mercury is released [44]. Also, soil moisture, vegetation and precipitation have some influence on the concentration of mercury [45]. Mercury is easily enriched in water, so it is an indicator of seismicity that can be observed from the mercury concentration changes in the wells (springs) in the fault zone. The concentration of mercury in groundwater is affected by a variety of factors, such as the lithology of the surrounding rock, the redox of water, the temperature, the total organic content, the number of suspended particulates and the conductivity of the aquifer $[46,47]$. Annual variation is the most common characteristic of mercury concentration, with a higher value in summer and a lower value in winter [48]. Like hydrogen, the concentration of mercury always has a higher value before an earthquake, which is always several times that of the background value. For example, before the Ninglang M 5.4 earthquake of Yunnan province in 1988, the mercury concentrations in the Yanyuan well and the Xichang well, about 200 $\mathrm{km}$ from the epicenter, began to rise to several times that of the background value, which continued for nearly 100 days [23]. According to the abnormal duration of mercury concentration and its range of distribution, it is possible to estimate the magnitude and onset time of the coming earthquake. Zhang et al. [23] suggested that the anomalous range of mercury increases with the magnitude of the earthquake, and the anomalous range for the $M \leq 5.0$ earthquake is limited to $200 \mathrm{~km}$. Therefore, mercury observation can play a significant role in the earthquake short- term monitoring and forecasting. physical representations of earthquakes are considered, following the theoretic system of hypotheses described by Gilat A and Vol A. [49] This hypothesis system can explain all the actual facts about earthquakes and volcanic eruptions, which the theoretic system of hypotheses of Reid H.F. could not explain with the hypothesis of an earthquake as a result of the displacement of rocks with accumulated elastic stress. The Reid model has problems in explaining the numerous geophysical and geochemical anomalies that precede and accompany earthquakes. The simplest physical and mathematical models of a short-focus earthquake associated with the diffusion of an explosive gas in all directions from the earthquake source, which will allow us to 
obtain a formula for estimating the time interval of an earthquake precursor. The piezoelectric conductivity equation in the theory of filtration (describing the motion of a gas in a porous medium) is written as follows;

$$
P t=æ \Delta P .
$$

where piezo conductivity coefficient $æ=(0.1 \sim 5)$ $\mathrm{m}^{2} / \mathrm{s}$; this range for $æ$ was fixed for various environments. The accumulation of gas mass in the trap can be interpreted as the appearance of an instantaneous point source of mass $m_{0}$, which begins to diffuse the gas in space. Then, the gas $\mathrm{P} \quad(r, t)$ can be described by the formula (if the origin is placed in the earthquake source).

$$
P\left(r, t+=E o \exp \frac{-\frac{r 2}{4 æ}}{\frac{8(\pi æ t) 3}{2}},\right.
$$

where $E 0=\frac{M o K g T k}{U}, M o$ is the mass of gas in the focus, $u(\mathrm{CH} 4)=2.663442 \times 10-26 \mathrm{~kg}, \mathrm{~kg}$ is Boltzmann constant, $\mathrm{T} \mathrm{k}$.is temperature. The gas density $u(r, t)$ can be described by the formula (if the origin is placed in the earthquake source) in the following form:

$$
\begin{aligned}
& U(r, t)=M 0, \exp \frac{-\frac{r 2}{4 \pi æ}}{8\left(\frac{(\pi æ t) 3}{2}\right)} \\
& U(O, T)=U 1=\frac{M o}{\frac{M\left(\frac{(\pi æ T) 3}{2}\right)}{\left(\left(\frac{\pi}{2}\right)\right.}}
\end{aligned}
$$

where $U 1$ is the gas density at which an earthquake occurs, for example, (for $\mathrm{CH} 4$ and air) $U 1=0.08(\mathrm{~kg} / \mathrm{m} 3)$. The earthquake energy $E$ is equal to:

$$
E=K 1 M_{0}
$$

The formula linking magnitude $\mathrm{M}$ and energy of earthquakes was presented in such form:

$$
\operatorname{Lg}\left(\frac{E}{J}=6.5+1.449 M\right.
$$

where $\mathrm{E}$ is the earthquake energy, $\mathrm{J}$ is one joule. Then the formula for the time precursor of the earthquake T, using (2)-(6), can be written as following:

$$
T=\frac{10 \quad 4.333+0.966 \cdot m\left(\frac{\mathrm{J}}{\mathrm{J} 1 \mathrm{U} 1}\right)^{2}}{3} .
$$

$\mathrm{T}$ was calculated as $=19$ hours, using (7) and $M=3, K 1=\frac{2.76 M J}{K g}$

$\mathrm{U} 1=\frac{0.08 \mathrm{~kg}}{\mathrm{~m} 2}, æ=\frac{0.1169 \mathrm{~m} 2}{\mathrm{~s}}$.

$\operatorname{Lg}(T)=a+b M$,

where $a$ and $b$ are free parameters. Thus, the derived formula (7) coincides in functional structure with the empirical formula (8). Based on the derivation of the formula for the time precursor of the earthquake $\mathrm{T}$ in equation 7 , the authors write the time precursor of the earthquake $T_{1}$ when thevibro-seismic device creates an oscillation with amplitude $a$ and frequency $\dot{\omega}$

$T_{1} / T=1 /\left(1-a c_{0}\right)^{2 / 3}$

Where;

$c_{0}=\dot{\omega} \quad c \rho \mu_{0} /\left(2 k_{B} T_{k} U_{1}\right),\left(c_{0}=0.625 \mu \mathrm{m}^{-1}\right) .(10)$ is constructed using formulas (7)-(8). Vibration exposure slows the release of gases and oxygen. As a result of a decrease in the emission of gases will play a greater role, which should lead to an even greater violation of the necessary earthquake conditions and, consequently, to an even greater decrease in the magnitude of the earthquake. Thus, it was proposed to fix the epicenter of the earthquake with the help of a new sensor. Then the authors turn on vibrator in the epicenter of an earthquake. The essence of this invention is to carryout periodic registration of the precursor of an earthquake in the set area of control. In order to do this, the magnitude of the density of mercury in the gas variability ascending from the Earth is registered at a depth of not less than $1 \mathrm{~m}$. Then, according to an anomalous change of the density value over time, the possibility of an earthquake can be forecast. In the described patent, the mercury variability can come from any direction into one sensor. the flow of mercury from any direction of a certain solid angle $\Omega 0$, comes into only one sensor. The number of sensors located in the hemisphere is $N=2 \pi / \Omega 0$. Thus, once the deltashaped gas flow from the fault fills all the traps in the region, the gas begins to diffuse in all directions from all the traps in the region. Now, looking at the gas flows in the entire set of sensors in the hemisphere, the authors can immediately determine the sensor with the maximum gas flow from all traps in the region and find the solid angle from which the maximum 
gas flow came to every station from all earthquakes. Considering together the maximum gas flows from several stations located in the region, the epicenters and hypocenters of future earthquakes can be determined. [34].

\subsection{Hydrogen}

Hydrogen has characteristics of being lightweight, slightly soluble, extremely and easily mobile, etc. The content of hydrogen in the atmosphere is very low, with a stable concentration of $0.5 \mathrm{mg} / \mathrm{dm}^{3}$. Previous studies suggested that there may be a huge amount of hydrogen which may have been sealed inside the earth when it was initially formed and released from the active fault $[50,51,52]$. In 1980 , Wakita et al. [53] found the correlation between the changes in hydrogen concentration and fault activities. Thereafter, scientists in USA observed that hydrogen escaped from the San Andreas Fault and found that it was associated with micro seismic activity $[54,55,56,57]$. Since then, more and more studies on fault hydrogen observation for earthquake monitoring have been made in some countries $[58,59]$.

The occurrence of hydrogen anomalies on fault systems has been recognized only relatively recently. Nagata (1979) found a strong hydrogen response in both shallow and deep groundwaters to a micro-earthquake swarm on the Izu Peninsula (Japan); he also reported a weaker response to the later 1978 Izu-Oshima-Kinkai earthquake. Sugisaki and Sugiura. [60], in an analysis of soil and spring gases, determined highly variable concentrations of hydrogen, and other gases, within and between faults, depending on rock type and on fault activity. This study also found greater enrichment of hydrogen in soil gases than were typically found in groundwater discharges. The application of hydrogen as an indicator of impending seismic activity was prompted by the detection of hydrogen anomalies, either prior to or simultaneous with seismic activity $[61,60]$. Monitoring programs typically employ discrete sampling of gas from groundwater and subsequent analysis by gas chromatography. Results of these efforts have shown variable hydrogen enrichments, but there is little agreement regarding the timing or amplitude of the anomalies and the associated seismic events. activity. Recent analyses of hydrogen in fault gases have shown that hydrogen can be enriched in these gases by more than four orders of magnitude above that present in air [53].
Repeated analyses at narrowly spaced sampling points along these faults found orders of magnitude variation in concentrations from place to place and over short time intervals. Both groups of investigators have postulated that a genetic relationship exists between fault activity and hydrogen generation. Sugisaki and Sugiura, [60] have also suggested that a correlation exists between the age of fault activity and hydrogen concentrations, but that the rock type and degree of alteration can affect the concentrations of hydrogen present, regardless of the age of activity. Ware et al. (1985) confirmed the latter result in hydrogen surveys on several fault systems, both inactive and very recently active, but found little correlation between age of activity and hydrogen content. They suggest that both hydrothermal activity and oxidation of iron hydroxide are capable of generating strong enrichments of hydrogen, independent of age of movement on a particular fault. Isotopic analysis of hydrogen in fault gases [53] indicated that its depth or origin was $20 \mathrm{~km}$, or possibly much less, suggesting a relatively shallow origin for the hydrogen. Hydrogen concentrations have been monitored for precursory variations in a number of fault systems, using either discrete sampling and laboratory analysis [60] or continuous monitoring of ground gas, using hydrogensensitive fuel cells [58,62] (1986). Results suggest that increases in hydrogen concentrations can occur either prior to or simultaneous with seismic activity. Sugisaki and Sugiura, [60] also reports a general correlation between hydrogen concentrations and earthquake magnitudes, but Satake et a/. (1985) and Sato et al. [57,62] find more variable hydrogen responses to both the magnitude and intervening distance of earthquakes and creep events. Precursory changes in groundwater chemistry are often attributed to mixing of fluids from two or more chemically distinct aquifers. This mechanism has the advantage of being able to account for not only increases in dissolved ion or gas concentrations [24], but also for concentration decreases [53,63,33] and for concurrent temperature changes that accompany chemical anomalies [64,63]. The precise mechanism of fluid mixing is most often suggested to be precursory fracturing of hydrologic barriers between isolated aquifers that allows them to subsequently mix (Sibson, 1981; $[33,24]$. Because the characterization of chemically distinct water sources requires analytical data for several different ions or isotopes, a clear demonstration of the mixing hypothesis has seldom been achieved. The two 
studies which best demonstrate groundwater mixing are those of Craig et a/. [65]; 1981) and King and others (King et al.., 1981; [66]. Craig's investigation used gas concentrations and isotopic abundances to show that several thermal springs and wells discharged mixtures of deep crustal fluids and shallow meteoric components, and that precursory changes in fluid compositions were the result of increasing contributions of the deep component to the total flow. King and coworkers suggested a similar conclusion from dissolved ion and hydrogen and oxygen isotopic data. Several other monitoring programs, although not reporting full data sets, have shown that coincident changes in chemical composition, temperature, and water level or flow rate often occur $[67,68,69,70,71,72,73,33,74]$. The reported anomalies include examples of falling chloride and cation concentrations that are accompanied by decreasing temperatures and increasing flow rates or water levels $[67,24]$, Li et al., 1985), or declining radon concentrations that are accompanied by falling temperatures $[53,70,71]$. Hence, the chemical and hydrologic observations strongly suggest that mixing of chemically distinct groundwaters is the predominant effect responsible for many of the decreases in ion concentrations as well as the substantial increases in dissolved ion concentrations observed. The physical mechanism responsible for the mixing of fluids is, however, not well established. Laboratory investigations have shown that rock porosities increase substantially when loaded to near their failure stress $[75,76,77,78]$. However, resistivity and permeability changes indicate that most of the fracture porosity created is not interconnected $[77,78,79]$ and that the absolute increase in matrix permeability is still very small $[76,78]$. Other investigations, conducted on jointed or artificially cutting samples, have reported increases or decreases in fluid flow through existing fractures of several hundred percent, in response to small changes in stress normal to, or parallel to, the joint face $[76,78]$. The permeability response of clays or other faultgouge materials to changes in stress, and their impact on these results is, as yet, unclear [76]. Nonetheless, the question of whether far-field stress changes would be sufficient to generate the permeability changes required to allow large scale mixing of groundwaters remains a serious impediment to the general application of this model. Other uncertainties about this mechanism include how such mixing could be accomplished without massive displacement of groundwaters, and how aquifer breaching could account for episodic precursors that show short-term concentration changes that subsequently return to normal baseline levels. Significant questions still remain regarding the ability of far-field stress changes to effect broad scale fluid mixing between separate aquifers. An alternative physical mechanism that I believe might more effectively account for groundwater chemical precursors is based on the changes in hydraulic head that have been observed in wells prior to, or concurrent with, some earthquakes $[80,81]$. The physical and chemical composition of a mixed fluid discharged from a Well or spring that draws fluids from two or more chemically and thermally distinct aquifers is critically dependent upon the hydraulic head within each aquifer. A change in the relative pressures among the aquifers, brought about by a precursory stress change, could substantially alter the discharge chemistry without requiring large scale mixing of fluids away from the fluid discharge conduit. An attractive feature of this mechanism is that it can account for episodic anomalies and for cyclic variations in fluid chemistry that have a tidal frequency [60], Sugisaki and Sugiura, 1986); earth-tide driven fluctuations in hydraulic heads of subsurface aquifers have been widely documented $[82,81]$. Such fluctuations could generate periodic chemical variations in spring dis- charges for an indefinite period of time, without causing progressive or irreversible changes in the up-flow zone, as would be required by the PC and IRSA models. The field and laboratory data suggest that fluid mixing can account for precursory changes in water chemistry as well as associated changes in temperature, flow rate, and water level that have been widely observed. Although the precise mechanism that produces these changes has not been established, it is suggested that variations in differential hydraulic head between distinct feed zones may account for episodic and cyclic changes, but that permanent or long-term changes in the physical (e.g., temperature, flow rate, head pressure) or chemical characteristics of a water source may be the result of barrier breaching between formerly separate aquifers.

\section{CONCLUSION}

From the literatures reviewed thus far, it is suffices to say that enhancing rock fissure and fracture base on the characteristics of $\mathrm{H}_{2}, \mathrm{Rn}$, $\mathrm{Hg}$, microelement, tracer isotope element and other gas components can reveal the possible precursory anomalies in the short-term stage of seismogenic process. The findings from literature 
reviewed also show that technical methodologies and mathematical modeling, strengthen the link between ground radon, mercury, hydrogen concentration anomalies and geodynamical events, measurements of radon, hydrogen and mercury gas in soil and in ground as seen in the work of (Gi Immè, 2010), Morelli, (2012) carried out a study and the results indicate that radon and mercury are good indicators of crustal activity such as earthquakes.

It has also been seen that Nigeria is no more aseimic as previous researches have shown. The seismic record of Nigeria from 1933-2021 have demonstrated in contrast to the idea, numerous quakes have been recorded in Nigeria over the years. Theoretical knowledge of geochemistry, geochemical observation of faults gas has become a hotspot once more in recent years. $\mathrm{Rn}, \mathrm{Hg}, \mathrm{H}_{2}$, etc., are used for geochemical observations. ${ }^{222} \mathrm{Rn}$ has a half-life of 3.825 days, a magnitude 5.0 earthquake will be detected by means of precursory phenomena at a distance not greater than $142 \mathrm{~km}$. Mercury plays an important role in revealing the relationship between fluid in the fault zone and the occurrence of earthquakes, the range for a magnitude 5.0 earthquake is limited to $200 \mathrm{~km}$. Hydrogen concentrations have been monitored for precursory variations in a number of fault systems, using either discrete sampling and laboratory analysis or continuous monitoring of ground gas, using hydrogen-sensitive fuel cells.

\section{COMPETING INTERESTS}

Authors have declared that no competing interests exist.

\section{REFERENCES}

1. Nemesio MP, Hernandez PA, Igarashi G, Trujillo I, Nakal S, Sumino H, Wakita $H$, Searching, Detecting Earthquake Geochemical Precursors in $\mathrm{CO}_{2}$ Rich Groundwaters from Galicia, Spain. Geochemical Journal. 2008;42:7583.

2. Center for Geodesy and Geodynamics Website Under National Space Research and Development Agency. Retrieved August $20^{\text {th }} ; 2021$

3. Ghosh D, Deb A, Sengupta R. Pronounced soil-radon anomaly - precursor of recent earthquakes in India, Radiation Measurements; 2007.

DOI:10.1016/j.radmeas. 2006.12.008

4. Holliday JR, Rundle JB, Tiampo KF, Klein W, Donnellan A. Systematic procedural and sensitivity analysis of the pattern informatics method for forecasting large (M $\geq 5$ ) earthquake events in southern California, Pure and Applied Geophysics. 2005;49(3):(in press).

5. Hycienth $\mathrm{N}$, Orji O. An Overview of Earthquakes and Tremors in Nigeria: Occurrences, Distributions and Implications for Monitoring. International Journal of Geology and Earth Sciences; 2018;4:56.

6. Oluwafemi JO, Ofuyatan OM, Ede AN, Oyebisi SO, Akinwumi II. Review of Earthquakes in Nigeria: An Understudied Area. International Journal of Civil Engineering and Technology. 2018;9(8):1023-1033,

7. Morelli $D$, Immè $G$, Altamore I, Cammisa S, Giammanco S, La Delfa S, Mangano G, Neri $M$, Patanè $G$.. Radionuclide measurements, via different methodologies, as tool for geophysical studies on Mt. Etna. Nuclear Instruments and Methods in Physics Research A; 2012.

DOI NIMA 10.1016/j.nima.201.021.172.

8. Song SR, Chen YL, Liu CM. Hydro chemical Changes in Spring Waters in Taiwan: Implications Evaluating Sites for Earthquake Precursory Monitoring. TAO. 2005;16(4):745-762.

9. Song SR, Ku WY, Ceng YL. Hydrogeochemical anomalies in the springs of the Chiayi Area in West-central Taiwan as possible precursors to earthquakes. Pure and Applied Geophysics. 2006;163: 675-691.

10. Wattananikorn K, Kanaree M, Wiboolsake S. Soil gas radon as an earthquake precursor: some considerations on data improvement. Radiation Measurements. 1998;29(6):593-598.

11. Zhang L, Fu H. Study on the relationship between $M \geq 6.0$ earthquakes and hydrochemistry precursory anomalies in Yunnan region. Earthquake Res. Plateau. 2000;12(1): 42-49.

12. Zoback MD, Byerlee JD. The Effect of Cyclic Differential Stress on Dilatancy in Westerly Granite Under Uniaxial and 
Triaxial Conditions. Journal of Geophysical Research. 1975b;80(11): 1526-1530.

Available:10.32937/IJGES.4.4.2018.56-76.

13. Koretsky C. The significance of surface complexation reactions in hydrologic systems: a geochemist's perspective. Journal of Hydrology. 2000;230:127-171.

14. Martinelli G. Fluido-dynamical and chemical features of radon 222 related to total gases: implications on earthquakes prediction topics. IAEA-TECDOC-726 Isotopic and geochemical precursors of earthquakes and volcanic eruptions Proceedings of an Advisory Group Meeting held in Vienna. 1991:48-62.

15. Mubarak MA, Riaz MS, Awais M, Jilani Z, Ahmad N, Irfan M, Javed F, Alam A, Sultan M. Review of Earthquake Prediction: A Global Review and Local Research. Proc. Pakistan Academic Science. 2009;46(4):233-246.

16. Wang $B$, Liu $Y$, Sun $X$, Ma $Y$, Zhang L, Ren $H$, Fang Z. Hydrogeological and Geochemical Observations for Earthquake Prediction Research in China: A Brief Overview. Pure and Applied Geo-Physics; 2018.

Available:https://doi.org/10.1007/s00024018-1885

17. Akpan OU, Yakubu TA. A Review of Earthquake Occurrences and Observations in Nigeria* Centre for Geodesy and Geodynamics, Toro 740103, Nigeria. Earthquake Science. 2010;23: 289-294.

18. Tsalha MS, Lar UA, Yakubu TA, Umar AK. and Duncan, D. The Review of the Historical and Recent Seismic Activity in Nigeria. Journal of Applied Geology. 2015:4:56-76.

19. Eze CL, Sunday VN, Ugwu SA, Uko ED. Ngah SA. Mechanical Model for Nigerian Intraplate Earth Tremors, JO-Earthzine; 2011.

Available:http://earthzine.org/2011/05/17.

20. Adepelumi A, Onibiyo O, Isogun M. "Shortterm probabilistic forecasting of earthquakes occurrence in South-Western Nigeria," Environtropica, 2010;1-11.

21. Cui YJ, Du JG, Zhang DH, Sun YT. Application of remote gas geochemistry in earthquake prediction. Advance in Earth Science. 2012;27(10):1173-1177.

22. Singh S, Kumar A, Bajwa BS, Mahajan S, Kumar V, Dhar S. Radon monitoring in soil gas and ground water for earthquake prediction studies in North West Himalayas, India. Terrestrial Atmospheric and Oceanic Sciences. 2010;21(4):685695.

23. Zhang W, Shen CS, Xing YA, Wei JZ, Wu $R G$, Ju HP. A new index of short-term and imminent earthquake anomalies-content of mercury. Earthquake Researching China. 1988;5(4):13-19.

24. Cai ZH. Earth tides and seismic waves recorded by the level fluctuations in a deep borehole at Wali near Beijing. Acta Seismologica Sinica. 1980;2(2):205-214.

25. Sabol J, Weng PS. Introduction to radiation protection dosimetry. World Scientific, Singapore; 1995.

26. Gauthier PJ, Condomines M. ${ }^{210} \mathrm{~Pb}-{ }^{226} \mathrm{Ra}$ radioactive disequilibria in recent lavas and radon degassing: inferences on the magma chamber dynamics at Stromboli and Merapi volcanoes. Earth and Planetary Science Letter. 1999;172:111126.

27. Rikitake T. Earthquake prediction developments in solid earth. Geophysics. 1976; 9:357-358.

28. Ramola RC, Sing S, Virk HS. The correlation between radon anomalies and magnitude of earthquakes. Nuclear Tracks Radiat. Meas. 1988;15:689-692.

29. Dobrovolsky IP, Zubkov SI, Achkin VI. Estimation of the size of earthquakes preparation zone. Paleoph. 1979;117:1217.

30. Hauksson E. Radon content of groundwater as an earthquake precursor: evaluation of worldwide data and physical basis. Journal of Geophysical Research. 1981a;86:9397- 9410 .

31. Friedmann H. Selected problems in Radon measurement for earthquake prediction Proceedings of the Second workshop on Radon Monitoring in Radioprotection, Environmental and/or Earth Science, Furlan, G. and Tommasino, L. (Ed.) World Scientific. 1991;307-316:1025-1044.

32. Hauksson E, Goddard JG. Radon earthquake precursor studies in Iceland. Journal of Geophyscal Research. 1981b;86(8):7037-7054

33. Barsukov VI, Varshal GM, Garanin AB, Serebrennikov VS. Hydrochemical Precursors of Earthquakes. Earthquake Prediction, UNESCO, Paris. 1984;169180. 
34. Noppe MG. On Reducing the Magnitude of an Impending Catastrophic Earthquake. International Journal of Geosciences. 2019;10:1037-1048.

35. Meng GK, He KM, Ban T, Jiao DC. Study on activity and segmentation of active fault using measurements of radon and mercury gases. Earthquake Research in China. 1997;13(1):43-51.

36. Wang, D. The dynamic abnormal variation of underground fluid in the north Tian Shan mountain before and after earthquakes with more than Ms 7 in Xinjiang and its adjacent areas. Inland Earthquake. 2004;18(1): 45-55.

37. Zhang B, Fang Z, Liu YW, Yang XH, Zhao $G$, Jing $Y$. Relationship between water temperature anomaly and earthquake in Yunnan. Earth Science-Journal of China University of Geosciences. 2014a;39(12):1880-1886.

38. Zhang L, Liu YW, Guo LS, Yang DX, Fang $Z$, Chen $T$. Isotope geochemistry of mercury and its relation to earthquake in the Wenchuan earthquake fault scientific drilling project hole-1 (WFSD-1). Tectonophysics. 2014b;619:79-85.

39. Xu ZQ., Li, H. B. and Wu, Z. L. Wenchuan earthquake and scientific drilling. Acta Geologica Sinica. 2008;82(12):1613-1622.

40. Li HB, Wang H, Xu ZQ, Si JL, Pei JL, Li TF. Characteristics of the fault-related rocks, fault zones and the principal slip zone in the Wenchuan earthquake fault scientific drilling project hole-1 (WFSD-1). Tectonophysics. 2013;584:23-42.

41. Cheng JJ. Elementary analysis of relationship between mercury anomaly of fault product gas and active fault. Crustal Deformation and Earthquake. 1997;17(2):97-100.

42. Chi QH. Abundance of mercury in crust, rocks and loose sediments. Geo-chimica. 2004;33(6): 641-648.

43. Li Y, Du JG, Wang FK, Zhou XC, Pan XD, Wei RQ. Geochemical characteristics of soil gas in Yanqing-Huailai basin. Acta Seismological Sinica. 2009;31(1):82-91.

44. Klusman RW, Jaacks JA. Environmental influences upon mercury, radon and helium concentrations in soil gases at a site near Denver, Colorado. Journal of Geochemical Exploration.1987;27(3):259280.

45. Tao SF, Wang CL, Liu YW, Jiang DY, Shen KJ, Ning Z. ZA preliminary experimental study on interference factors of soil gas. Northwestern Seismological Journal. 1992;14(1):92-95.

46. Bagnato E, Aiuppa A, Parello F, D'alessandro W, Allard P, Calabrese S. Mercury concentration, speciation and budget in volcanic aquifers: Italy and Guadeloupe (LesserAntilles). Journal of Volcanology and Geothermal Research. 2009;179(1):96-106.-y

47. Johannesson $\mathrm{KH}$, Neumann $\mathrm{K}$. Geochemical cycling of mercury in a deep, confined aquifer: Insights from biogeochemical reactive transport modeling. Geochimicaet Cosmochimica Acta. 2013;106:25-43.

48. Che YT, Yu JZ, Liu CL, Sun TL. Study on influence distance of some interference sources around the station to the behavior of underground fluid. Recent Developments in World Seismology. 2006;4:10-16.

49. Gilat $A$, Vol A. Degassing of Primordial Hydrogen and Helium as the Major Energy Source for Internal Terrestrial Processes. Geoscience Frontiers. 2012;3:911-921.

50. Gold T, Soter S. The deep-earth-gas hypothesis. Scientific American. 1980;242(6):154-161.

51. Du LT, Chen AF, Wang J, Huang ST. Earth's hydrogen removal. Bulletin of Mineralogy, Petrology and Geo- chemistry. 1995;3:193-195.

52. Chen F. Hydrogen-the important source of fluid in earth interior. Earth Science Frontiers. 1996;3(34):72-79.

53. Wakita $H$, Nakamura $Y$, Kita I, Fujii $N$, Notsu K. Hydrogen release: New indicator of fault activity. Science. 1980;210(4466):188-190.

54. McGee K, Casadevall $T$, Sato $M$. Hydrogen gas monitoring at Long Valley Caldera, California Menlo Park, Geological Survey. 1982:1-12.

55. McGee K, Sutton A, Sato M. Correlation of hydrogen gas emissions and seismic activity at Long Valley Caldera, California. Eos, Transactions, American Geophysical Union. 1983;64(45): 891.

56. Ware $\mathrm{RH}$, Roecken $\mathrm{C}$, Wyss $\mathrm{M}$. The detection and interpretation of hydrogen in fault gases. Pure and Applied Geophysics. 1984;122(2-4):392-402.

57. Sato M, Sutton A, McGee K, Robinson RS. Monitoring of hydrogen along the San 
Andreas and Calaveras faults in central California in 1980-1984. Journal of Geophysical Research. 1986; 91(12):12315-12326.

58. Sato M, McGee KA. Continuous monitoring of hydrogen on the south flank of Mount St. Helens. US Geological Survey Professional Paper. 1981;1250:209219.

59. Satake $\mathrm{H}$, Ohashi M, Hayashi $\mathrm{Y}$. Discharge of $\mathrm{H} 2$ from the Atotsugawa and Ushikubi faults, Japan, and its relation to earthquakes. Pure and Applied Geophysics. 1984;122(2-4):185-193.

60. Sugisaki R, Sugiura T. Geochemical indicator of tectonic stress resulting in an earthquake in central Japan, 1984. Science. 1985;229(4719):1261-1262.

61. Li Q, Fu H, Mao HL, Zhu RH, He DQ. Study on the relationship between abnormal water temperature and earthquake in Yunnan area. Journal of Seismological Research. 2017;40(2):233240.

62. Sato M, Sutton A, McGee K. Anomalous hydrogen emissions from the San Andreas fault observed at the Cienega Winery, central California. Pure and Applied Geophysics. 1985;122(2-4):376-391.

63. King CY, Zhang W, Zhang ZC. Earthquake-induced groundwater and gas changes. Pure and Applied Geophysics. 1981;163(4):633-645.

64. Craig H, Chung Y, Poreda R, Lupton J, Damasceno $S$. Investigation of radon and helium as possible fluid-phase precursor to earthquakes. U.S. Geological Survey Open-file Report no. 1981;81278:36.

65. Craig H, Chung Y, Poreda R, Lupton J. Damasceno $S$. Fluid phase earthquake precursor studies in Southern California. Eos, Transactions of the American Geophysical Union. 1980;61(46):10351036.

66. O'Neil JR, King CY. Variations in stableisotope ratios of ground waters in seismically active regions of California. Geophysical Resources Letter. $1981 ; 8(5): 429-432$.

67. Jiang $\mathrm{FL}, \mathrm{Li}$ GR. The application of geochemical methods in earthquake prediction in China. Geophysical Resources Letter. 1981a;8(5):469--472.

68. Jiang FL, Li GR. Experimental studies of the mechanisms of seismo-geochemical precursors. Geophysical Resources Letter. 1981b;8(5):473-476.

69. Wakita H. Precursory Changes in Ground Water Prior to the 1978 Izu-Oshima-Kinkai Earthquake. In Earthquake Prediction: An International Review, American Geophysical Union, Maurice Ewing Series. 1981;4:527-532.

70. Wakita H. Changes in Groundwater Level and Chemical Composition. in Earthquake Prediction Techniques. Chapter 8, (T. Asada, Ed.) (University of Tokyo Press). 1982;175-216.

71. Wakita H. Groundwater observations for earthquake prediction in Japan. International Symposium on Continental Seismicity and Earthquake Prediction, Seismological Press. 1984;494-500.

72. Mei S. Short Term and Immediate Precursors to Continental Earthquakes in China. International Symposium on Continental Seismicity and Earthquake Prediction, Seismological Press. 1984;440461.

73. Zhu F, Quan Y, Gu H, Xu X, Guan X. Reexamination of the anomalous phenomena taken as precursors before the Longling $g$ earthquake of 1915. International Symposium on Continental Seismicity and Earthquake Prediction, Seismological Press. 1984;57:1-581.

74. Li G, Jaing F, Wang J, Zhang $P$. Preliminary Results of Seismogeochemical Research In China. 1985;122:218-230.

75. Zoback MD, Byerlee JD. The Effect of Microcrack Dilatancy on the Permeability of Westerly Granite. Journal of Geophysical Research. 1975a;80(5):752755.

76. Brace WF. Recent Laboratory Studies of Earthquake Mechanics and Prediction. U.S. - Japanese Seminar on Earthquake Precursors, Tokyo, Japan. 1977;185-202.

77. Brace WF. Volume Changes During Fracture and Frictional Sliding: A Review. 1978a;116:603-614.

78. Brace WF. A Note on Permeability Changes in Geologic Material due to Stress. 1978b;116:627 633.

79. Wang, C.-Y., Sundaram, P. N. And Goodman, R. E. Electrical Resistivity Changes In Rocks During Frictional Sliding And Fracture. 1978; 116:717-731.

80. Roeloffs E. Hydrologic Precursors: A Critical Review. This Volume; 1987. 
81. Roewffs E, Rudnicki JW. Coupled Deformation-Diffusion Effects on Water Level Changes due to Propagating Creep Events.1985;122:560-582. 82. Roewffs E, Bredehoeft JD. Coseismic
Response of Water Wells Near

Parkfield, California, to the August 4, 1985 North Kettleman Hills Earthquake. (Abstract) Eos, Transactions of the American Geophysical Union. 1985; 66:986.

(c) 2021 Wuyep et al.; This is an Open Access article distributed under the terms of the Creative Commons Attribution License (http://creativecommons.org/licenses/by/4.0), which permits unrestricted use, distribution, and reproduction in any medium, provided the original work is properly cited.

Peer-review history:

The peer review history for this paper can be accessed here: https://www.sdiarticle4.com/review-history/72897 